\title{
ULNAR WRIST PAIN IN DISTAL END RADIUS FRACTURES PREVENTED BY PROPHYLACTIC CORTICOSTEROID INJECTION
}

\author{
Ashok Ghodke1, Alfven Vieira², Rahul Vanjari³, Vicky Jain ${ }^{4}$, Apoorv Dua ${ }^{5}$ \\ ${ }^{1}$ Assistant Professor, Department of Orthopaedics, MGM Medical College and Hospital, Navi Mumbai. \\ 2Professor and HOD, Department of Orthopaedics, MGM Medical College and Hospital, Navi Mumbai. \\ ${ }^{3}$ Chief Resident, Department of Orthopaedics, MGM Medical College and Hospital, Navi Mumbai. \\ ${ }^{4}$ Chief Resident, Department of Orthopaedics, MGM Medical College and Hospital, Navi Mumbai. \\ ${ }^{5}$ Senior Resident, Department of Orthopaedics, MGM Medical College and Hospital, Navi Mumbai.
}

\section{ABSTRACT}

\section{BACKGROUND}

Common complication of Distal Radius fracture is ulnar sided pain. The simplest method for decreasing pain is corticosteroid injection. The present study was designed to assess the effect of corticosteroid injection in the prevention of ulnar sided wrist pain.

\section{MATERIALS AND METHODS}

In this clinical trial patients with distal radius fractures scheduled for closed reduction and percutaneous pin fixation were divided into control and corticosteroid groups. In the corticosteroid group, the patient received a single Triamcinolone Acetate injection in the dorsoulnar side of the wrist before reduction, while the control group received placebo. The patients were to be followed for at least 6 months.

\section{RESULTS}

Eighty two patients were followed for 6 months. At the end of the 3 months follow-up, the difference between the two groups about the number of individuals without ulnar sided wrist pain was statistically significant $(\mathrm{P}=0.038)$, so that less patients in the control group were painless, while this was not the case in the 6 months follow-up ( $\mathrm{P}=0.507)$, but in the both time frames the mean grip power, visual analogue pain score and the Disabilities of the Arm, Shoulder and Hand (DASH) score showed statistically significant difference between the two groups, so that the corticosteroid groups demonstrated greater power grip and less scores in pain and DASH $(\mathrm{P}<0.05)$.

\section{CONCLUSION}

Based on the findings of the present study it seems that prophylactic corticosteroid injection will be associated with a decrease in the severity of wrist pain in patients with acute distal radius fractures. With regard to the decrease in the number of painless individuals, it seems that the decrease is not persistent. Overall, the need for a study with longer follow-up is obvious.

\section{KEYWORDS}

Pain, Distal Radius Fracture, Steroid, Wrist.

HOW TO CITE THIS ARTICLE: Ghodke A, Vieira A, Vanjari R, et al. Ulnar wrist pain in distal end radius fractures prevented by prophylactic corticosteroid injection. J Evolution Med Dent Sci 2016;5(5):283-286, DOI: 10.14260/jemds/2016/61

\section{INTRODUCTION}

Distal radius fractures are one of the most common fractures that an orthopaedic surgeon may encounter the most common complaint of these patients is persistent ulnar sided wrist pain. ${ }^{[1],[2]}$ and in one study $71 \%$ of patients complained of it.[3] The etiology of ulnar sided wrist pain in these patients may be instability of distal radioulnar joint, arthritis of the joint or damage to Triangular Fibrocartilage Complex (TFCC).[4] Fractures of common cause of instability of the distal radioulnar joint and the most common cause of damage to TFCC and injection of corticosteroid is a simple and usually the first step in decreasing the ulnar sided wrist pain in TFCC and ligaments injury and even joint instability. ${ }^{[5]}$

Financial or Other, Competing Interest: None.

Submission 16-12-2015, Peer Review 17-12-2015,

Acceptance 02-01-2016, Published 18-01-2016.

Corresponding Author:

Dr. Ashok Ghodke,

MGM Medical College and Hospital,

Sector-1, Kamothe,

Navi Mumbai-410209,

Maharashtra,

India

E-mail: ghodke.ashok@gmail.com

DOI:10.14260/jemds/2016/61
We studied the effect of prophylactic injection of corticosteroids in the ulnar side of the wrist in patients with extra-articular distal radius fractures.

\section{MATERIALS AND METHODS}

The present study was a double blinded clinical trial, performed on the patients with extra-articular distal radius fractures from September 2014 to September 2015. The patients and the physician who was in charge of the study of follow-up were blinded about the group of treatment and did not know which patient belongs to which group. The inclusion criteria were those who gave written and informed consent, age $>18$ years, extra-articular fracture of distal $2.5 \mathrm{~cm}$ of radius without comminution (Type A1) [Figure 1], presence of pain in the ulnar side of wrist and no underlying disease that could affect the process of bone healing and no contraindication for use of corticosteroids.

The null hypothesis was that the injection of corticosteroid in the area of ulnar styloid has no effect on late pain in this area. For sample size calculation, we considered type one error and power at 0.05 and 0.80 . Based on a pilot study and formula for sample size that compares means in two groups, estimated sample size at each group was 30. 
We included all subjects in 1 year. Our final comparisons confirmed that selected sample size was adequate to reveal differences between two groups. The patients entered the study after the necessary explanation about the goals, method of the study, method of blinding, possible side effects; followup by the researcher and filling the recent consent forms. The patients were randomized into corticosteroid and placebo groups by getting out one of the ten similar envelopes, five containing the word placebo and five with the word corticosteroids.

All of the envelopes were to be changed after enrolling ten patients. Randomization was performed by a surgeon who performed the operations. The corticosteroid group had a single injection of corticosteroid Triamcinolone Acetate in the region of styloid process of ulna into TFCC, while the placebo group received injection of distilled water (2cc), [Figure 2]. The distal radius fracture was managed by closed reduction and percutaneous pin fixation [Figure 3]. The patients were discharged after $24 \mathrm{~h}$ of intravenous antibiotics and control of swelling. The first postoperative visit was 2 weeks later and then on 1-month for pin and cast removal if everything was perfect. Then the patients were followed up for the 3 and 6 months postoperative visits. In the 3 and 6 months follow-up, Disabilities of the Arm, Shoulder and Hand (DASH) score questionnaire and Visual Analogue Scale (VAS) and grip strength test were done and recorded.

DASH score questionnaire has 30 questions that measures the function of the upper limb. VAS contained a spectrum of the patient's ulnar sided pain with two ends: No discomfort ( 0 points) and extremely severe pain (10 points) and the patient would score his pain verbally. Pain would mean ulnar sided pain in activity, rest or touch. Grip strength test was done by Jamar dynamometer device and pressing the handle would show the amount of grip pressing force. Finally, data entered computer and analyzed.

\section{RESULTS}

Ninety four patients were eligible to participate in this study, but 82 gave informed consent and finally completed the 6 months follow-up period, 39 of the patients were in control group (Placebo) and 43 patients were in corticosteroid group [Flowchart 1 [Additional file 1]]. No case of malunion (Radial shortening, angulation) was observed. These two groups did not show statistically significant difference with regard to age and sex. Ulnar styloid was broken in 45 patients, 22 in the control group and 23 in the corticosteroid group (Chi-square test $\mathrm{P}>0.05$ ). In the 3 months follow-up, 35 patients reported no ulnar sided wrist pain, 12 in the control and 23 in the corticosteroid group (Chi-square $\mathrm{P}=0.038$ ). Rest of them had some degree of pain in the ulnar side of their wrist. In the 6 months follow-up, 41 patients did not report any ulnar sided wrist pain, 18 in the control group and 23 in the corticosteroid group (Chi-square test $\mathrm{P}=0.507$ ).

In both of these follow-up periods, the difference of mean pain score was statistically significant between the two groups (pain score R effect size respectively was 0.430 and 0.324 ). Also, the difference of pain score between 3 and 6 months of follow-up was statistically significant in the control group. However, this was not the case with corticosteroid group [Table 1]. Grip strength was measured and compared in both of these groups and showed statistically significant difference in both.
In the control group the mean grip strength at 3 months follow-up was $61.53 \pm 8.63$ and $97.09 \pm 11.20$ in the corticosteroid group ( $\mathrm{r}=0.80$ ). In 6 months follow-up, the mean grip strength was $70.38 \pm 14.22$ in control group and $97.09 \pm 11.20$ in corticosteroid group ( $\mathrm{t}$-test $\mathrm{P}<0.001, \mathrm{r}=0.730$ ). Comparison of DASH score of patients in three and 6 months of follow-up showed statistically significant difference between two groups: $33.56 \pm 2.34$ in control versus $16.90 \pm 4.25$ in corticosteroid group in 3 months $(r=0.659)$ and $15.80 \pm 3.94$ versus $8.77 \pm 4.13$ in 6 months followup $(r=0.80)$. At the end of 6 months followup, all of the patients had complete range of motion of wrist and fingers [Figure 4] and [Table 3].

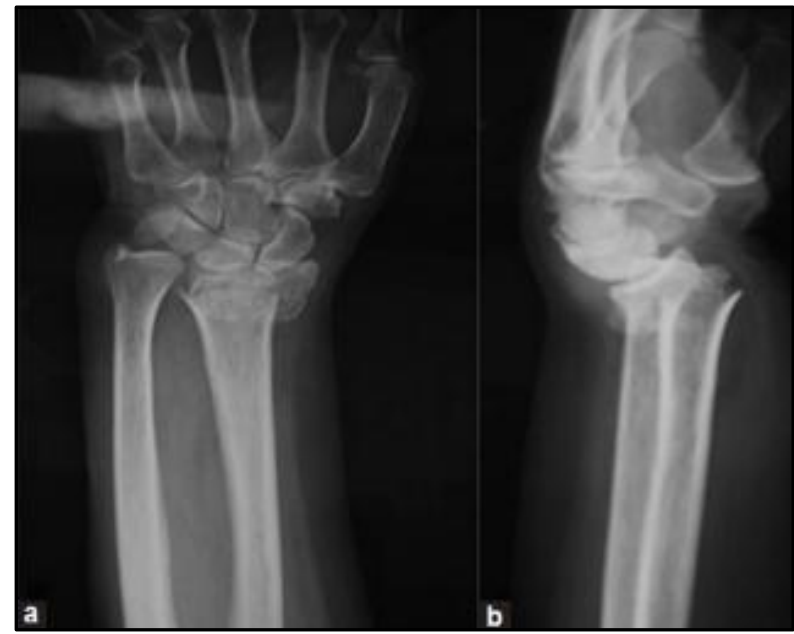

Fig. 1: X-ray of Left wrist joint showing anteroposterior and lateral views shows showing typical extra-articular distal radius fracture

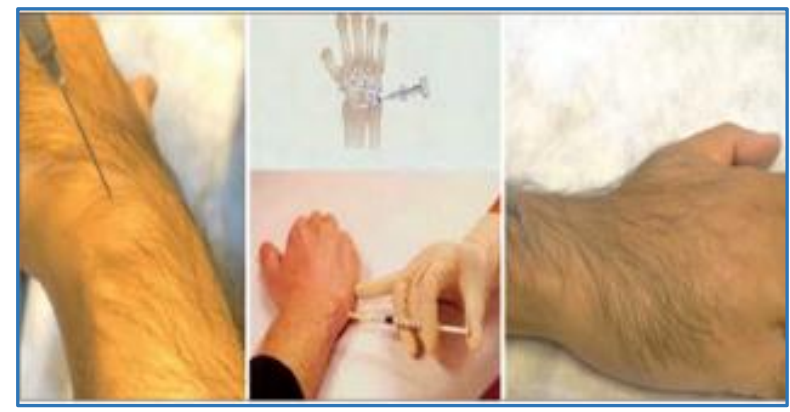

Fig. 2: Clinical photograph and schematic presentation of injection site

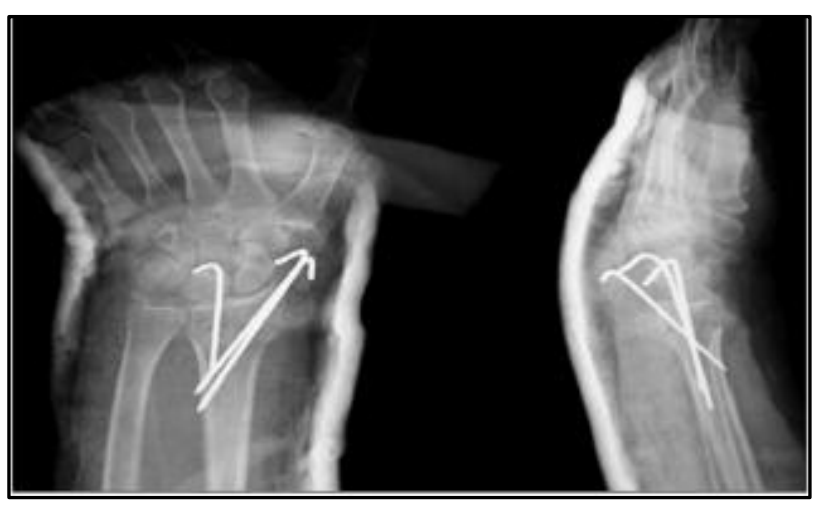

Fig. 3: Post-operative X-ray, anteroposterior and lateral view of same patient showing a distal radius fracture with $K$ wires in situ 


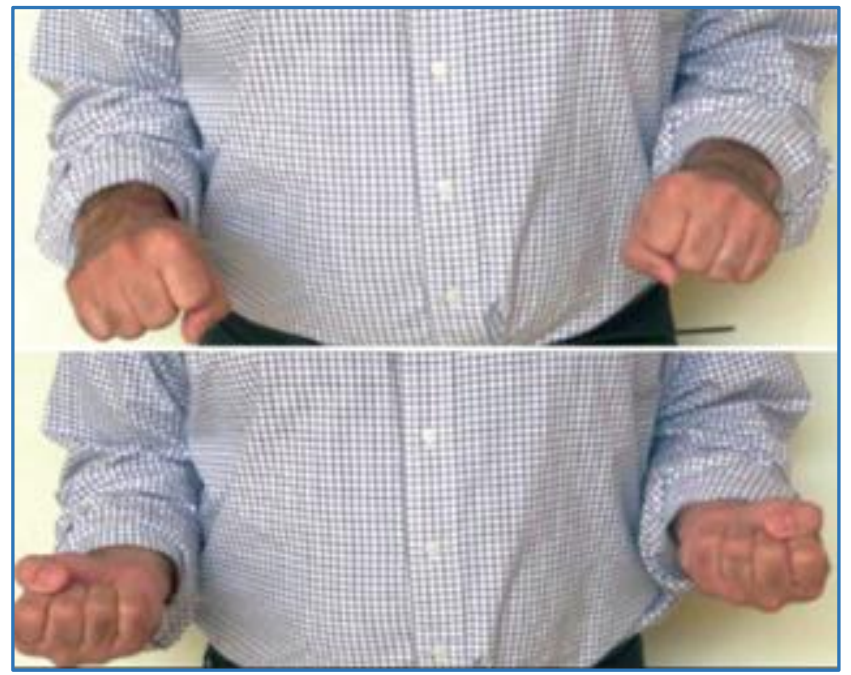

Fig. 4: Clinical photographs showing full range of wrist and finger motion after the initial fracture

\begin{tabular}{|lccc|}
\hline & $\begin{array}{c}\text { 3 months } \\
\text { followup } \\
\text { pain score }\end{array}$ & $\begin{array}{c}\text { 6 months } \\
\text { followup } \\
\text { pain score }\end{array}$ & $\begin{array}{c}\text { Mann-Whitney } \\
\text { U-test } P\end{array}$ \\
\hline Control $(n=39)$ & $2.39 \pm 1.89$ & $1.92 \pm 1.88$ & 0.033 \\
Steroid $(n=43)$ & $1.41 \pm 1.09$ & $0.95 \pm 1.21$ & 0.204 \\
Mann-Whitney U-test $P$ & 0.002 & 0.029 & \\
\hline
\end{tabular}

Table 1: Comparison of pain scores

\section{DISCUSSION}

The most important finding of the present study was a persistent decrease in the severity of ulnar sided wrist pain in patients with distal of radius fractures that had received prophylactic injection of corticosteroid. In fact in 6 months of follow up, percentage of patients experiencing some pain was similar in two groups but the patients who had injections felt less pain.

Significant decrease in grip power and DASH score increase in the control group is justifiable, because both power grip and doing usual works with the upper limb needs a painfree hand. As it was observed, improvement was seen in both of these two variables by decrease in pain with time and in 6 months of followup.

In the present study, there was no association between fracture of styloid and ulnar sided wrist pain. Many studies have noticed the roll of ulnar styloid fracture in distal radius fractures. One study concluded that the fracture of styloid of ulna would indicate a poor prognosis for ulno-carpal complaints of patients.[6] Another study found worse results in patients with ulnar styloid fracture. ${ }^{[7]}$ On the other hand, many studies didn't show this and they didn't find any relation between ulnar styloid status and the final result.[8],[9],[10],[11] But it should be considered that there is no uniformity among these studies and some of them focused on displaced fractures fixed with plate and screws, ${ }^{[8],[9]}$ another one were performed on fractures treated by pinning. ${ }^{[7]}$ and the other focused on the fractures, which were fixed with external fixation.[11] Again variables of the studies were different too, in a way that the reader should refer to the original articles. In fact, in the past surgery has been considered for nonunion of styloid.[12]

But recent studies have noticed that ulnar styloid nonunion is usually asymptomatic and cannot explain the ulnar sided wrist pain.[13]
An interesting finding of the present study was a decrease in severity pain in both groups with time, more obvious in the control group, so that some patients joined the pain-free group in followup. One may conclude that if the patients were followed for a longer time, even the difference of severity of pain would have minimized between the two groups. Although, decrease in the number of patients with ulnar sided pain after distal radius fractures with time is the finding of other authors too.[3] It is interesting that these findings were more evident in the control group and in the 3 month period between the follow-ups the pain score had a greater decrease in this group [Table 1].

Corticosteroid injection is used to treat injuries of TFCC, instability of distal radio-ulnar joint and even injuries of lunotriquetral ligament.[14]

\begin{tabular}{|lccc|}
\hline & $1-5$ years & $6-10$ years & $11-15$ years \\
\hline Number & 22 & 31 & 26 \\
Males/females & $10 / 12$ (NS) & $18 / 13$ (NS) & $19 / 7$ (NS) \\
Mean fracture & & & \\
(0-distal, 1-proximal) & 0.37 (NS) & 0.31 (NS) & $0.12(P<0.05)$ \\
Mean Cl & 0.79 (NS) & $0.76(\mathrm{NS})$ & 0.77 (NS) \\
\hline NS-Not signAcant, Cl-Castindex & & & \\
\hline
\end{tabular}

Table 2: Summary of the findings of the study

Actually prophylactic injection of corticosteroid could decrease the prevalence and severity of pain at least for a short time. But it seems that this effect has been temporary, and the interesting point is the similar experience of other authors about the temporary effect of corticosteroid injection in ulnar sided wrist pain.[15]

In the present study, all of the patients were treated by percutaneous pining and casting. It may be considered that with newer devices such as plate and screws, better results for treatment of such fractures have become possible and this may seem a pitfall of the study. But it should be considered that we compared the groups with similar treatment methods and on the other hand even the recent studies have not found any difference in the final function of the patients who were treated with pin or plate.[16] Although, return to the normal function may be more rapid using the plate in a short term, in the long term it is not the case, and the function will be similar.[17],[18]

Is the use of plate and screws associated with a reduction in wrist pain after distal radius fractures? Up to the best of our knowledge, just one study has addressed this subject.[19] Although this study didn't have a control group, at the end of 18 months follow-up, a significant percentage of patients still had pain and the interesting point is that the radial side pain was more common than the ulnar sided. Again the reduction in the number of patients who had pain and decrease in severity of pain with time was another finding of this study.

The most important limitation of the present study is the short followup. Again the lack of arthroscopy made it impossible to have a definite diagnosis of injuries and the reason of the pain in the patients with ulnar sided wrist pain. In conclusion, according to the results of the present study, it seems that injection of corticosteroid in region of styloid process of ulna in patients with distal radius fractures who are treated with percutaneous pining and casting may reduce the incidence and severity of ulnar sided wrist pain in short term, 
though probably this would not be the case with time, at least with regard to the number of painless patients.

\section{REFERENCES}

1. Altissimi M, Antenucci R, Fiacca C, et al. Long term results of conservative treatment of fractures of the distal radius. Clin Orthop Relat Res 1986;202-10.

2. Roumen RM, Hesp WL, Bruggink ED. Unstable Colles' fractures in elderly patients. A randomised trial of external fixation for redisplacement. J Bone Joint Surg Br 1991;73:307-11.

3. Cheng HS, Hung LK, Ho PC, et al. An analysis of causes and treatment outcome of chronic wrist pain after distal radial fractures. Hand Surg 2008;13:1-10.

4. Tsukazaki T, Iwasaki K. Ulnar wrist pain after Colles' fracture 109 fractures followed for 4 years. Acta Orthop Scand.

5. Zyluk A, Piotuch B. Distal radioulnar joint instability: A review of literature. Pol Orthop Traumatol 2013;78:7784.

6. Krämer S, Meyer H, O'Loughlin PF, et al. The incidence of ulnocarpal complaints after distal radial fracture in relation to the fracture of the ulnar styloid. J Hand Surg Eur Vol 2013;38:710-7.

7. Belloti JC, Moraes VY, Albers MB, et al. Does an ulnar styloid fracture interfere with the results of a distal radius fracture? J Orthop Sci 2010;15:216-22.

8. Zhao L, Wang BJ, Li YD, et al. Clinical followup study of ulnar styloid fractures and classification of distal radial fractures. Beijing Da Xue Xue Bao 2011;43:675-80.

9. Scheer JH, Adolfsson LE. Radioulnar laxity and clinical outcome do not correlate after a distal radius fracture. J Hand Surg Eur Vol 2011;36:503-8.

10. Kim JK, Koh YD, Do NH. Should an ulnar styloid fracture be fixed following volar plate fixation of a distal radial fracture? J Bone Joint Surg Am 2010;92:1-6.
11. Chen YX, Zheng X, Shi HF, et al. Will the untreated ulnar styloid fracture influence the outcome of unstable distal radial fracture treated with external fixation when the distal radioulnar joint is stable. BMC Musculoskelet Disord 2013;14:186.

12. Hauck RM, Skahen J 3rd, Palmer AK. Classification and treatment of ulnar styloid nonunion. J Hand Surg Am 1996;21:418-22.

13. Buijze GA, Ring D. Clinical impact of united versus nonunited fractures of the proximal half of the ulnar styloid following volar plate fixation of the distal radius. J Hand Surg Am 2010;35:223-7.

14. Watanabe A, Souza F, Vezeridis PS, et al. Ulnar-sided wrist pain. II. Clinical imaging and treatment. Skeletal Radiol 2010;39:837-57.

15. Buterbaugh GA, Brown TR, Horn PC. Ulnar-sided wrist pain in athletes. Clin Sports Med 1998;17:567-83.

16. Hull P, Baraza N, Gohil M, et al. Volar locking plates versus $\mathrm{K}$-wire fixation of dorsally displaced distal radius fractures - A functional outcome study. J Trauma 2011;70:E125-8.

17. Karantana A, Downing ND, Forward DP, et al. Surgical treatment of distal radial fractures with a volar locking plate versus conventional percutaneous methods: a randomized controlled trial. J Bone Joint Surg Am 2013; 95:1737-44.

18. Grewal R, MacDermid JC, King GJ, et al. Open reduction internal fixation versus percutaneous pinning with external fixation of distal radius fractures: a prospective, randomized clinical trial. J Hand Surg Am 2011;36:1899-906.

19. Kurimoto $S$, Tatebe $M$, Shinohara $T$, et al. Residual wrist pain after volar locking plate fixation of distal radius fractures. Acta Orthop Belg 2012;78:603-10. 